\title{
CIDADANIA, MOVIMENTOS SOCIAIS E CRIMES NA SOCIEDADE EM REDE
}

\author{
CITIZENSHIP, SOCIAL MOVEMENTS AND CRIMES IN THE NETWORK \\ SOCIETY
}

\author{
${ }^{1}$ Caio Sperandeo De Macedo \\ ${ }^{2}$ Greice Patricia Fuller
}

\section{RESUMO}

O presente trabalho analisa os movimentos sociais organizados pela internet neste início de século XXI enquanto legitimados no primado da cidadania e da autodeterminação dos cidadãos, bem como aborda aspectos criminais e a necessidade de que os mesmos tenham fundamento na Constituição Federal de 1988 para que sejam considerados lícitos. Outrossim, referendar que eventuais condutas praticadas pelos movimentos sociais podem se caracterizar como delitos, vez que muitas vezes adotam estratégias estigmatizantes e discriminatórias, no contexto do discurso do ódio.

Palavras-chave: Cidadania, Movimentos sociais, Crimes, Internet, Sociedade em rede

\begin{abstract}
This paper analyzes the social movements organized through the Internet at the beginning of XXI century while legitimated in the rule of citizenship and self-determination of citizens, as well as addresses criminal aspects and the need for them to be founded in the Constitution of 1988 in order to be considered licit. Furtheremore, ratify that some acts committed by social movements can be characterized as delicts, as often adopt stigmatizing and discriminatory strategies in the context of hate speech.
\end{abstract}

Keywords: Citizenship, Social movements, Crimes, Internet, Network society

\footnotetext{
${ }^{1}$ Doutor em Direito pela Pontifícia Universidade Católica - PUC, São Paulo, (Brasil). Professor pela Faculdade Metropolitana Unidas - FMU, São Paulo, Brasil. Sócio-Proprietário da Caio Sperandeo de Macedo Advocacia e Consultoria Jurídica, CSMACJ, Brasil. E-mail: caio.csm@terra.com.br

${ }^{2}$ Pós-Doutoranda Direito pela Universidad de Navarra, Pamplona, Espanha. Professora na Faculdade Metropolitana Unidas - FMU, São Paulo, Brasil. Professora dos Cursos de Graduação das Faculdades de Direito e Economia e Pós-Graduação Lato Sensu de Direitos Difusos e Coletivos e Direito Contratual da Pontifícia Universidade Católica de São Paulo - PUC, São Paulo, Brasil. E-mail: greicepf@uol.com.br
} 


\section{INTRODUÇÃO}

O tema escolhido visa analisar o conteúdo principiológico da cidadania e as influências das redes digitais sobre os movimentos sociais deflagrados neste início de século XXI, mormente em face dos crimes praticados no contexto fático de suas manifestações. Outrossim, o tema inerente ao "ciberativismo", ou seja, à utilização da internet como instrumento de veiculação dos movimentos sociais é estudado segundo os fundamentos e princípios constitucionais e posteriormente, sob o viés da cibercriminalidade, especialmente, no que tange aos crimes denominados de ciberterrorismo, neonazismo digital e outros envolvendo qualquer ordem de racismo ou discriminação no âmbito do uso das tecnologias de informação.

Justifica-se a escolha temática em face de seu aspecto vanguardista junto à realidade jurídico-fática brasileira e seu dramático caráter pernicioso que implica em segregação e afronta aos princípios da cidadania e dignidade da pessoa humana, no contexto da Sociedade que se comunica em redes.

Ademais, observou-se durante a análise encetada no trabalho o método indutivo, partindo-se da análise empírica, normativa e doutrinária para o reconhecimento do necessário e específico estudo sobre o tema.

\section{CONCEPÇÃO DE HANNAH ARENDT SOBRE CIDADANIA.}

A concepção de cidadania desenvolvida por Hannah Arendt em meados do Século XX continua a se revelar como de grande utilidade para entender as transformações sociais e políticas que vêm experimentando as incipientes democracias contemporâneas como a do Brasil, pois tem por intento resgatar valores prioritários consagrados no pacto social fundamental celebrado entre o Estado e seus cidadãos, no sentido de que o cidadão vem antes do Estado(o Estado é para o cidadão e, não o contrário).

Rememora, outrossim, que as conquistas políticas se consubstanciam na vontade e no agir conjunto dos cidadãos que expressam sua liberdade de associação, de acesso à informação, de opinião e de manifestação do pensamento no espaço público, 
com o intuito de participar do processo político e influenciar decisões de Governo, bem como fiscalizar o exercício do poder em prol da sociedade.

Assim, ponderar sobre o escólio de Hannah Arendt permite contextualizar o surgimento do poder entre os cidadãos e sua mediação com o Estado; permite restaurar o primado da cidadania como o agir conjunto dos homens, no espaço público, que têm consciência política de contribuir na formação das decisões e dos desígnios do Estado, em concretizar direitos constitucionalmente previstos em consonância com os interesses e prioridades da sociedade.

Ou seja, analisar a ação conjunta dos homens(no sentido de agir) como uma potência iniciadora legítima ligado ao entendimento contemporâneo de exercício de cidadania, plenamente albergado em diversos dispositivos da nossa Constituição Federal de 1988, sem que isso implique desmerecer a mediação povo-governo exercida predominantemente pelas agremiações partidárias, através de seus representantes eleitos.

Neste sentido, refletir sobre a afirmação de Hannah Arendt (2010, p.9) quanto à condição humana, de que: “A ação seria um luxo desnecessário, uma caprichosa interferência nas leis gerais do comportamento, se os homens fossem repetições interminavelmente reproduzíveis do mesmo modelo, cuja natureza ou essência fosse a mesma para todos e tão previsível quanto a natureza ou essência de qualquer coisa".

Em outros termos, analisar a capacidade de ação direta(autodeterminação) como contribuição fundamental para o Estado democrático de direito, legitimada pela articulação concertada entre os cidadãos, que se reconhecem como iguais(interação horizontal) para realizar algo em prol da sociedade; categoria de ação que manifesta a liberdade política e valoriza que as pessoas expressem publicamente sua opinião.

Outrossim, reconhecer as demais conclusões que Hannah Arendt (2010, p.220221) tributa ao “agir", vez que: "É com palavras e atos que nos inserimos no mundo humano e essa inserção é um segundo nascimento, no qual confirmamos e assumimos o fato simples do nosso aparecimento físico original". Sendo certo que(Arendt, 2010, p.220-221) “a ação e o discurso são os modos pelos quais os seres humanos aparecem uns para os outros, certamente não como objetos físicos, mas qua homens”.

Não obstante a peculiaridade temporal efêmera do agir em conjunto, que se dá na interação entre homens, para que seu processo seja deflagrado se faz necessário também existência do que Hannah Arendt chama de ‘domínio público’ ou, em outras 
palavras, espaço público, que não se vincula obrigatoriamente com a noção geral de uma localidade geográfica no espaço e no tempo.

Tanto isso é verdadeiro, que hoje em dia é cediço que Governos e Instituições podem ser pressionados e até destituídos pelo "agir", pela iniciativa de mudança e sentimento de empoderamento gestado e deflagrado pelos cidadãos no "espaço público arendtiano" contido na cibernética, notadamente pela comunicação através das redes sociais digitais e internet, como estão a revelar inúmeras manifestações cívicas recentes vivenciadas ao redor do mundo e cuja mais marcante ficou conhecida como Primavera Árabe ${ }^{1}$.

Referido espaço de aparência telemático e seus múltiplos recursos são utilizados na intersubjetividade da comunicação e organização das manifestações encetadas por seus participantes e simpatizantes; para o tempo em que vivemos, é o espaço privilegiado (mais utilizado) no qual as pessoas se comunicam e se reconhecem não como coisas vivas ou objetos, mas como outro se revela como Ser, compartilhando livremente ideias e ideais que vicejam em seu espírito.

Não se olvide que embora a mobilização dos participantes se dê basicamente pelos instrumentos telemáticos, as manifestações recentes da sociedade civil desaguam em ocupação dos espaços públicos urbanos(ruas, praças; pontes, avenidas, parques, edifícios e monumentos públicos; passseatas etc) para demonstrar seu inconformismo.

\footnotetext{
${ }^{1}$ A este respeito, trazemos observações de BINGEMER, L. Maria Clara, em artigo "Primavera Árabe e Advento", publicado em 30/11/2011, no Jornal do Brasil: “(...)Entende-se, portanto, por que os protestos que eclodiram no mundo árabe a partir de 2010 e que até hoje permanecem foram batizados de Primavera Árabe. Iniciando-se na Tunísia, em 18 de dezembro de 2010, o movimento rapidamente se espalhou pelo norte da África e também pelo Oriente Médio, encontrando talvez sua manifestação mais forte, além da própria Tunísia, no Egito e na Líbia. Ali, naqueles dois países, foram derrubados regimes de exceção que pareciam até então muralhas inexpugnáveis. Dentre os três chefes de Estado assim removidos do poder, o tunisino Bem Ali fugiu, o egípcio Mubarak renunciou e o terceiro, Kadafi, foi capturado, torturado por rebeldes, arrastado por carreta em público e executado com um tiro na cabeça. Os protestos tomaram diversas formas e utilizaram diversas técnicas, como greves, manifestações, passeatas, resistência civil em campanhas reivindicatórias e comícios. As mídias sociais como o Facebook, Twitter, YouTube foram largamente usadas para apoiar a movimentação e convocar a população, informando-a e sensibilizando-a a fim de que não se deixasse enganar ou envolver pelo que os Estados objeto dos protestos espalhavam pela mídia: censura e desinformação.(...) É, inegavelmente, o fim de uma era e de uma forma de organização política que tem como consequência uma renovação profunda naquela parte do mundo onde proliferavam os regimes fortes e autocráticos. A Primavera Árabe é a primeira revolução democrática acontecida no mundo árabe no século em que vivemos. (...) Os protagonistas deste primaveril movimento são jovens, e isso chama a atenção. Não em vão os protestos do Egito receberam o nome de Revolução da Juventude. Além disso e por isso, são informados, bem formados, e muitos têm estudos universitários. Sabem usar as redes sociais e comprovam, com o sucesso e a rápida difusão de seu movimento, que realmente o mundo tornou-se plano com a chegada da internet e a comunicação em rede. É o novo que chega ao mundo árabe e, embora infelizmente com um importante saldo de violência e morte, traz vento e perfume libertador. Por isso, o tempo litúrgico do Advento, vivido hoje pela Igreja Católica, é uma chave de leitura importante para iluminar nossa reflexão e vivência. Advento é aparecimento, chegada de alguém ou de algo. É algo que começa, se institui, rompe o estabelecido e traz um novo estado de coisas". Conforme: www.jb.com.br, sítio visitado em 19/07/2013.
} 
E Hannah Arendt(2010, p. 249) tem a complementar que "o espaço da aparência passa a existir sempre que os homens se reúnem na modalidade do discurso e da ação e, portanto, precede toda e qualquer constituição formal do domínio público e as várias formas de governo, isto é, as várias formas possíveis de organização do domínio público".

E a manutenção deste espaço potencial de aparência entre homens que se comunicam direta e livremente é definido como ‘domínio público' pela Autora, e tem ligação de causa-efeito com a geração do poder pelos cidadãos. Consciente desta dimensão prática do poder gerado pela atuação concertada dos cidadãos, Hannah Arendt(2010, p.250-251) assevera que:

(...) o poder passa a existir entre os homens quando eles agem juntos, e desaparece no instante em que eles se dispersam. (...) O único fator material indispensável para a geração do poder é a convivência entre os homens. Estes só retém poder quando vivem tão próximos uns aos outros que as potencialidades da ação estão sempre presentes. O que mantém unidas as pessoas depois que passa o momento fugaz da ação(aquilo que hoje chamamos de 'organização') e o que elas, ao mesmo tempo, mantém vivo ao permanecerem unidas é o poder.(...)

Sua única limitação é a existência de outras pessoas, limitação que não é acidental, pois o poder humano corresponde, antes de tudo, à condição humana da pluralidade.

Ao esclarecer o liame entre o espaço público e o poder como dependentes de cidadania, Celso Lafer(1997, p. 4) pontua que:

Como observou Habermas, Hannah Arendt, na sua reflexão, não se preocupou com a aquisição e a manutenção do poder, nem com o seu uso pelos governantes, mas sim com o que a isto antecede: a sua geração pelos governados. O potestas in populo ciceroniano, para ela, quer dizer o poder entendido como aptidão humana para agir em conjunto. Daí a importância decisiva do direito de associação para a comunidade política, pois é a associação que gera o poder de que se valem os governantes.

Referido autor (LAFER, 1979, p.37) reforça seu entendimento no sentido de:

Restaurar, recuperar, resgatar o espaço público que permite, pela liberdade de comunicação, o agir conjunto, e com ele a geração do poder, é o grande tema unificador de Hannah Arendt. Graças a este agir conjunto surge a política autêntica e, com ela, a dignidade da vida pública, que Hannah Arendt conseguiu iluminar mesmo num mundo como o contemporâneo, que viveu a experiência do totalitarismo e que se debate com o impasse do pensamento contemporâneo, sofre a trivialidade da administração das coisas e se desespera com as conjunturas difíceis. 
Portanto, adotando o ponto de vista de que a geração do poder reside no agir conjunto dos homens, contagiado pela força da opinião da maioria que conjuga de ideias e ideais semelhantes, que se comunicam horizontalmente no espaço público Arendtiano e se organizam em prol dos interesses da sociedade é que se compreende a dimensão da cidadania, mormente neste início de século XXI, quando potencializada pelas redes sociais digitais e demais meios de comunicação telemática.

Em palavras próprias, reforça Hannah Arendt (2013, p. 31) que:

\begin{abstract}
A participação dos cidadãos no governo, qualquer que seja a forma, só é tida como necessária para a liberdade por que o Estado, que necessariamente precisa dispor de meios de força, precisa ser controlado pelos governados no exercício dessa força. (...) O que hoje entendemos por governo constitucional, não importa se de natureza monárquica ou republicana, é, em essência, um governo controlado pelos governados, restringido em suas competências de poder e em sua aplicação da força (...).
\end{abstract}

E o "teste de força" do exercício da cidadania (e também da Democracia) nos dia de hoje consiste exatamente na possibilidade da sociedade se mobilizar livremente e demonstrar no espaço público seu inconformismo com atos administrativos deletérios, leis desarrazoadas ou decisões consideradas injustas e, por consequência, influenciar nas decisões políticas de Governo, de seus representantes no Parlamento (Congresso Nacional) e das demais esferas públicas.

Em outras palavras, reafirmar que a cidadania só se realiza plenamente através da participação política dos cidadãos na formação da vontade das decisões relevantes do Estado; bem como na conquista de novos direitos prestacionais; no controle e limites ao exercício do poder do Estado, em defesa do interesse público.

Analisando os acontecimentos com espírito de época, vislumbra-se a atualidade do conceito de 'espaço público' empreendido por Hannah Arendt, como demonstração da força indelével da sociedade mobilizada para o exercício de cidadania; demonstração visível de que a soberania popular tem força para opor-se ao Poder do Estado institucionalizado.

E a ocupação do espaço público arendtiano (que não se vincula obrigatoriamente com a noção cotidiana de um lugar no espaço e no tempo) pelo agir conjunto dos cidadãos, ao ganhar a opinião pública em defesa de uma causa justa, tem o condão de sensibilizar Governos, instituições e todo o espectro político que gravita em torno do 
poder a rever posições e corrigir rumos tão logo identifiquem que sua atuação confronta a maioria da sociedade.

\section{SOCIEDADE EM REDE E CIDADANIA.}

A sociedade em rede teve sua origem nos primeiros anos de Século XXI(CASTELLS, 2005, p.17/20), sendo oriunda da sociedade capitalista pós-industrial e tributária direta da sociedade da informação(surgida na metade final do século XX), que em síntese se assenta na visão das economias e fatores produtivos interligados em escala mundial, possibilitado por inovações tecnológicas como o microprocessador eletrônico, a fibra ótica, comunicação por satélites, e a rede mundial de computadores (internet); elementos que em decorrência deste contexto foram reunidos sobre a expressão "globalização".

Consoante apontamento de Jean-François Lyotard(1993, p.4), podemos dizer que estas novas conquistas tecnológicas fazem parte e já se encontram consolidadas na pósmodernidade ${ }^{2}$ e estabelecem novos paradigmas comportamentais e uma série de mudanças sociais, culturais e políticas observadas na sociedade contemporânea, notadamente em decorrência da disponibilidade de amplo acesso ao fluxo de transmissão de conhecimentos e informações que trafegam remotamente do espaço cibernético em tempo real, para qualquer lugar do mundo.

Como outro vértice da dimensão da indelével influência da sociedade em rede Manuel Castells(2005, p. 23) destaca sua importância como instrumento de formação da opinião pública a influenciar os processos de decisão política, vez que o fluxo de comunicação tem o condão de transformar o espaço público, ao possibilitar que as pessoas que recebem informação formem suas convicções como receptores coletivos. Em suas palavras:

Uma característica central da sociedade em rede é a transformação da área da comunicação incluindo os media. A comunicação constitui o espaço público, ou seja, o espaço cognitivo em que as mentes das pessoas recebem

\footnotetext{
${ }^{2}$ LYOTARD, Jean-François. p.4: "Na idade pós-industrial e pós-moderna, a ciência conservará e sem dúvida reforçará ainda mais sua importância na disputa das capacidades produtivas dos Estados-nações. (...). Sob a forma de mercadoria informacional indispensável ao poderio produtivo, o saber já é e será um desafio maior, talvez o mais importante, na competição mundial pelo poder. Do mesmo modo que os Estados-nações se bateram para dominar territórios, e com isto dominar o acesso e a exploração das matérias-primas e da mão-de-obra barata, é concebível que eles se batam no futuro para dominar as informações. Assim encontra-se aberto um novo campo para as estratégias industriais e comerciais e para as estratégias militares e políticas”.
} 
informação e formam os seus pontos de vista através do processamento de sinais da sociedade no seu conjunto. Por outras palavras, enquanto a comunicação interpessoal é uma relação privada, formada pelos actores da interacção, os sistemas de comunicação mediáticos criam os relacionamentos entre instituições e organizações da sociedade e as pessoas no seu conjunto, não enquanto indivíduos, mas como receptores colectivos de informação, mesmo quando a informação final é processada por cada indivíduo de acordo com as suas próprias características pessoais. É por isso que a estrutura e a dinâmica da comunicação social é essencial na formação da consciência e da opinião, e a base do processo de decisão política.

Em decorrência desta constatação, Manuel Castells(2005, p.24) desenvolve o conceito de "comunicação de massa autocomandada" para elucidar o poder da difusão de informação através das redes de novas tecnologias de comunicação e chamando à atenção para a característica de que a comunicação opera autonomamente à margem dos canais institucionais e governamentais que a sociedade normalmente se utiliza, o que acaba por transbordar sua influência na formação da opinião pública e, por consequência, para o processo político:

\footnotetext{
Com a difusão da sociedade em rede, e com a expansão das redes de novas tecnologias de comunicação, dá-se uma explosão de redes horizontais de comunicação, bastante independentes do negócio dos media e dos governos, o que permite a emergência daquilo que chamei de comunicação de massa autocomandada. É comunicação de massa porque é difundida em toda a Internet, podendo potencialmente chegar a todo o planeta. É autocomandada porque geralmente é iniciada por indivíduos ou grupos, por eles próprios, sem a mediação do sistema de media. A explosão de blogues, vlogues(vídeoblogues), podding, streaming e outras formas de interactividade. A comunicação entre computadores criou um novo sistema de redes de comunicação global e horizontal que, pela primeira vez na história, permite que as pessoas comuniquem umas com as outras sem utilizar os canais criados pelas instituições da sociedade para a comunicação socializante.

(...)

Uma vez que a política é largamente dependente do espaço público da comunicação em sociedade, o processo político é transformado em função das condições da cultura da virtualidade real. As opiniões políticas e o comportamento político são formados no espaço da comunicação.
}

Assim, através dos canais de mídia eletrônica possibilita-se aos cidadãos interlocução horizontal para debates e troca de opiniões, livre das idiossincrasias e restrições dos demais veículos de massa (TV, Rádio, Jornais) regulados através de concessão pública e supervisionados pelo Estado, ao viabilizar o amplo acesso de informações, interação entre os participantes conectados em rede e, portanto, o contraditório, enriquecendo a formação da opinião pública.

Não nos olvidando de acrescentar que a autonomia das escolhas dos cidadãos decorre das diversas interações tecnológicas de mídia digitais e tradicionais combinadas 
e interligadas(jornais; revistas; rádio, televisão; internet; redes sociais, SMS etc) para a formação da sua opinião e seu consequente exercício de cidadania.

Gustavo Cardoso(2007, p. 315/316) complementa com relação às possibilidades que a mídia contribui para o exercício da cidadania ao pontuar que:

\begin{abstract}
Analisando a sua contribuição para a reflexividade, Murdock $(1992,1993)$ identifica três formas de a mídia contribuir para o exercício da cidadania.

A primeira consiste na oferta de informação e aconselhamento sobre os seus próprios direitos. Em segundo lugar, a mídia fornece acesso a um vasto conjunto de informação, pontos de vista e debates sobre temáticas políticas e questões públicas. Em terceiro, a mídia faculta os meios para que os cidadãos possam expressar críticas e propor soluções alternativas às que lhes são apresentadas. Por último, na dimensão da experiência, a mídia constitui um referencial de representações, que tanto podem ser assimiladas quanto rejeitadas.
\end{abstract}

A mídia pode igualmente operar como instrumento de extensão da
cidadania(Murdock, 1992, 1993). Isso ocorre porque o surgimento da mídia
permitiu a reconfiguração das relações sociais e de poder. (...)

Murdock (1992, 1993) concede também à mídia o papel de garantia da cidadania, no sentido em que não é suficiente dispor de direitos. Caso não existam as condições básicas para exercer esses direitos é igualmente necessário que existam os recursos simbólicos que permitam denunciar essas situações.

Talvez se possa afirmar que a contribuição de Murdock $(1992,1993)$ de maior alcance para compreender a interação entre mídia e cidadania seja que as mídias, ao permitirem o estabelecimento de relações sociais com pessoas que nunca conhecemos previamente ou com quem nunca falamos face a face, introduziram uma nova forma de exercer a cidadania. É essa característica que permite a organização de indivíduos com objetivos comuns, embora partilhando espaços territoriais diversos.

A par disso, importante destacar que os elementos acima referidos foram potencializados para o exercício da cidadania pelas influências das novas mídias digitais. Em seu papel garantidor, portanto, a mídia e principalmente as novas mídias veiculadas pela sociedade em rede permitem a divulgação e esclarecimento de direitos, possibilitam ampliar os debates e manifestação de opiniões, abrem espaço para que os cidadãos possam expressar críticas e soluções, denunciar restrições e permitem, ademais, a organização de imenso contingente de pessoas desconhecidas entre si atuarem para consecução de objetivos comuns.

Entrementes, para a cidadania ser exercitada e fazer valer a autonomia possibilitada pela era da informação se faz necessário que a sociedade, as mídias, o Governo e o sistema político se utilizem deste aparato tecnológico para fins de integração e maior participação dos cidadãos no processo democrático. 


\title{
3. MOVIMENTOS SOCIAIS, REDES SOCIAIS E INTERNET.
}

Como aduz Ely Chinoi(1991, p.678-679), historicamente os movimentos sociais ${ }^{3}$ surgem de situações de tensão ou desorganização social. E em decorrência desse desarranjo, as pessoas tendem a ser receptivas a uma concepção de mundo que conteste ideias estabelecidas ou que compartilhe suas dificuldades individuais e grupais frente ao poder instituído e/ou aos acontecimentos que ocorrem em seu cotidiano.

Além disso, para o tempo que vivemos Manuel Castells(1999, p.93) observa que as influências das novas tecnologias da comunicação e da informação(TIC'S) também contribuem para o desarranjo dos mecanismos de controle social, como as tradicionais instituições do Estado, pois:

\begin{abstract}
À medida que as instituições do Estado e as organizações da sociedade fundamentam-se na cultura, história e geografia, a repentina aceleração do tempo histórico, aliada à abstração do poder em uma rede de computadores, vem desintegrando os mecanismos atuais de controle social e representação política.
\end{abstract}

Assim, pode-se dizer que a Internet e as redes sociais digitais por serem atualmente os meios de comunicação e interação social mais utilizado na sociedade, constituem-se nos principais veículos de interação entre movimentos sociais e seus simpatizantes, que compartilham mesmos valores e que podem dar apoio e eventualmente se engajar em seus propósitos.

Em termos de capilaridade e mobilização, as mídias digitais se revelam fundamentais para o sucesso dos atuais os movimentos sociais, do azo possibilitar estabelecer uma potenciação exponencial de relações sociais com pessoas que nunca conhecemos, permitindo a organização de indivíduos com objetivos comuns, ainda que

\footnotetext{
${ }^{3}$ BOBBIO, Norberto. MATTEUCCI, Nicola. PASQUINO, Gianfranco. Dicionário de Política, Vol I, tradução Carmen C. Varriale, Gaetano Lo Mônoco, João Ferreira, Luis Guerreiro Pinto Cacais e Renzo Dini. 11 a edição, Editora UnB, p.799. (...) “o sociólogo francês Alain Touraine afirma que "os movimentos sociais pertencem aos processos pelos quais uma sociedade cria a sua organização a partir do seu sistema de ação histórica, através dos conflitos de classe e dos acordos políticos" (1975, 397). Os fundamentos da teoria de Touraine são constituídos pelos três princípios da identidade, da oposição e da totalidade. Pelo princípio de identidade, o agente dá uma definição de si mesmo, caracteriza-se em confronto com outros agentes em meio de um conflito que os contrapõe no campo da ação social. "O conflito faz surgir o adversário, forma a consciência dos agentes que se defrontam" (415): este é o princípio de oposição. Finalmente, "o princípio de totalidade não é senão o sistema de ação histórica por cujo domínio lutam os adversários, entrincheirados na dupla dialética das classes" (416): quanto mais importantes forem os Movimentos sociais, tanto maior força terá o princípio de totalidade.
} 
em espaços territoriais longínquos diversos, a fim de atuar na consciência da sociedade, funcionado como elemento catalisador para mudanças sociais.

Ademais, a internet $\mathrm{e}$ as redes sociais permitem aos movimentos sociais interagir e trocar informações sobre as questões em discussão entre seus simpatizantes (e não simpatizantes); ostentam, outrossim, capacidade de interação com poder de circulação local, nacional ou globalmente, ensejando um processo autoreflexivo.

Sendo certo que as redes horizontais de comunicação, interativas, através das conexões digitais, constituem o principal eixo de sustentação para os movimentos sociais, podendo-se falar em um modus operandi padrão dos movimentos sociais na era da sociedade em rede; afirma-se também que todos os movimentos sociais deflagrados neste início de século XXI utilizam da comunicação telemática para promover seus propósitos.

Entre os caracteres comuns aos movimentos sociais do século XXI, compilados por Manuel Castells(2013, p.163-169), temos a destacar os seguintes: (i) são conectados em rede de múltiplas formas, com o uso das redes de comunicação da internet e dos telefones celulares, inclusive para formar redes dentro do movimento, com outros movimentos espraiados pelo mundo, com a mídia e a sociedade; (ii) embora sejam deflagrados pelas redes sociais e internet, concretizam-se como movimento ao ocupar o espaço público urbano (praças; interdição ruas; bloqueios, invasões de prédios públicos; protestos etc); (iii) criam um "espaço de autonomia" (híbrido entre a cibernética e os espaços urbanos), como nova forma espacial dos movimentos sociais em rede; (iv) os movimentos são locais e globais; pois aflora em seu contexto específico e se espraia pelo mundo pelas redes digitais; (v) os movimentos são espontâneos, pois sua origem parte de uma indignação ou injustiça de um ato específico ou de atos de governos; (vi) são virais, consoante a lógica da difusão de mensagens em rede e especialmente através da divulgação e emoção geradas pelas imagens de mobilização ou repressão; (vii) são movimentos sem liderança específica ou carismática, diante da normal desconfiança dos participantes com relação a eventual comando formal e rejeitam qualquer intermediação política, já que não se sentem representados; (viii) a relação horizontal das redes estimula a colaboração e solidariedade entre os pares, reduzindo a importância de uma liderança formal; o que também dificulta a repressão; (ix) são movimentos autoreflexivos, questionam permanentemente o que desejam e o que querem realizar e que transformação pretendem para a sociedade; (x) em regra, não são movimentos sociais programáticos(sem uma linha específica de atuação), pois costumam abrigar 
várias demandas complementares, salvo quando de propósito único; (xi) são movimentos sociais voltados para a mudança de valores da sociedade;(xii) costumam ser apolíticos, sem concepção doutrinária fundamental ou defesa dos sistemas políticos específicos(liberalismo, socialismo etc); (xiii) propõem uma nova cultura da sociedade em rede, concentrada na autonomia do sujeito em relação às instituições tradicionais da sociedade.

Dentre todas as características apontadas acima, Manuel Castells(2013, p.172) concentra sua ênfase na construção na individuação e na autonomia das pessoas, na liberdade do cidadão em definir seu projeto de vida independente das instituições da sociedade, segundo seus valores e interesses particulares. Consentâneo a essa posição, referido autor anota que a transformação mais profunda advinda da internet para este início de século XXI se concentra no desenvolvimento autônomo de redes sociais diversas, controladas e diversificadas pelos seus usuários.

Portanto, os movimentos sociais em rede têm como elemento marcante a cultura de autonomia, com valores e estilo de vida próprio a este novo século; e não poderiam surgir sem a cultura da liberdade e de autonomia, ínsita à logica de funcionamento randômico, anárquico e não hierárquico da comunicação e informações propagadas pela Internet, aptas para transformar a sociedade e suas instituições.

E as transformações politico-sociais em curso, advirão com maior ou menor vagar conforme a permeabilidade das instituições políticas em absorver estes novos tempos e ter disposição para negociar e absorver as mudanças advindas destas demandas sociais, que pressionam por reformar políticas diversas, conforme os contextos sociais vivenciados e que buscam alcançar aceitação da sociedade para encampar suas reivindicações.

Ademais, ao esclarecer o liame transformador dos movimentos sociais em rede, Manuel Castells(2013, p.177) destaca que seu maior poder opera sobre a consciência cívica da sociedade vez que:

\footnotetext{
O verdadeiro objetivo desses movimentos é aumentar a consciência dos cidadãos em geral, qualifica-los pela participação nos próprios movimentos e num amplo processo de deliberação sobre suas vidas e seu país, e confiar em sua capacidade de tomar suas próprias decisões em relação à classe política.
}

Mormente, por que na era informacional da sociedade que se comunica em redes, em virtude da disponibilidade de amplo acesso à comunicação horizontal intersubjetiva entre os cidadãos, o poder passa a se concentrar nos códigos da 
informação, que por sua vez criam novos códigos culturais que determinam o comportamento das pessoas, suas ideologias e suas formas de viver.

Por outro vértice, a possibilidade de transbordamento dos limites legais também não pode ser desconsiderada, do azo que uma vez deflagrada determinadas ações práticas pelos movimentos sociais, o controle sobre os excessos decorrentes da incitação e entorpecimento dos participantes e/ou da repressão estatal, muitas vezes têm descambado para condutas sectárias e odiosas, principalmente veiculadas pela internet $\mathrm{e}$ redes sociais, como os jornais cotidianamente estão a revelar.

\section{Movimentos sociais e crimes na era da internet.}

Atualmente o espaço chamado internet ${ }^{4}$ vem sendo cenário de movimentos sociais, sejam políticos, culturais ou de quaisquer outros conteúdos, cuja atividade passou a ser denominada de ciberativismo. Nesse ponto, se parte para a análise do uso das tecnologias de informação e comunicação (redes Facebook, twiter, blogs etc) como instrumentos para o desenvolvimento de movimentos sociais ${ }^{5}$ tendentes a vários e diferentes objetivos ${ }^{6}$.

\footnotetext{
${ }^{4}$ O conceito de internet vem determinado no Marco Civil da Internet" (Lei 12965/2014) informando:

"Art. $5^{\circ}$. Para os efeitos desta Lei, considera-se:

"I- internet: os sistema constituído do conjunto de protocolos lógicos, estruturado em escala mundial para uso público e irrestrito, com a finalidade de possibilitar a comunicação de dados entre terminais por meio de diferentes redes;

II- terminal: o computador ou qualquer dispositivo que se conecte à internet (...)"

${ }^{5}$ A primeira experiência de atuação do ativismo tecnológico foi a dos indígenas mexicanas zapatistas da região de Chiapas em 1994. Como afirmam Pimenta e Rivello, o movimento de indígenas zapatistas enviava comunicados a jornais e rádios para informar sobre o levante por direitos básicos que postulavam na região denominada Chiapas. As reivindicações eram repassadas na internet através de sites e e-mails, culminando em uma rede de posicionamento sobre o movimento espalhada em diversos países. O protesto tinha como objeto de reivindicação direitos locais, assim como caracterizava-se como uma denúncia das contradições envolventes no sistema econômico capitalista. In: PIMENTA, Francisco J. Paolielo; RIVELLO, Ana Paula Avellar. Zapatismo e ciberativismo: a busca de uma conexão perdida. Anais do XXXI Congresso Brasileiro de Ciências da Comunicação, 2008.

${ }^{6}$ Clay Shirky do Programa de Telecomunicações Interativas da Universidade de Nova York e autor do livro: A cultura da Participação, explica que, "graças à Internet, é possível termos uma organização global minúscula". Contudo, foi por meio de movimentos sociais criados pela formação de grupos de pessoas pela Internet que o coletivo estudantil sérvio Otpor conseguiu reunir 300 mil pessoas na passeata que depôs o presidente Slobodan Milosevi, em 2000; o movimento Massa Crítica, surgido na Califórnia e já espalhado por cerca de trezentas cidades do mundo (defende a bike como meio de transporte), reúne participantes na última sexta-feira de todo mês para uma pedalada de protesto na Av. Paulista, em São Paulo. In: TONON, Rafael; MIN, Marcelo. Faça sua reunião. Revista Galileu, n. 247, p. 36-43, fev. 2012. O mesmo ocorre na Av. Paulista, São Paulo que através da chamada nas redes sociais consegue reunir participantes pró e contra o atual governo brasileiro da presidente Dilma Roussef em dias adredemente marcados.
} 
A discussão nesse aspecto tem seu foco sobre os movimentos sociais ilegítimos na sociedade em rede, ou seja, movimentos que retrocedem à busca da chamada cidadania global inclusão digital. A internet enquanto instrumento de apropriação e empoderamento(MARTÍN-BARBERO, 2008) pode levar a situações de estigmatizações, a narrativas totalitárias e discriminatórias, construídas a partir de atores sociais que passam a compartilhar informações que tipificam condutas criminosas.

A internet compreendida como espaço de desenvolvimento de movimentos sociais pode sê-lo sob a perspectiva cultural, ou como "artefato cultural (FRAGOSO, RECUERO, AMARAL, p.42) $)^{7,}$, o que gera a inserção desta tecnologia na vida cotidiana, propiciando um canal frequente de interação entre o online e o offline.

A utilização da internet como instrumento de veiculação dos movimentos sociais deve se pautar sobre os fundamentos e princípios constitucionais presentes nos artigos $1^{\circ}, 3^{\circ}, 5^{\circ}, 6^{\circ}, 170215,216$, todos da Constituição Federal. Para além disso, vale ressaltar que:

\begin{abstract}
(...) o uso da internet encontra-se associado às relações econômicas organizadas constitucionalmente na forma dos artigos $1^{\circ}$, inciso IV e 170 e seguintes da Constituição Federal, recebendo tutela protetiva segundo os artigos $5^{\circ}$, inciso XXXII, 170, inciso V e 48 de suas Disposições Transitórias. Resta ainda estabelecer que o uso da internet por ser meio de comunicação social eletrônica (artigo 222, $\S 3^{\circ}$ da Constituição Federal) além da necessária observância dos artigos acima traduzidos, merece observar o disposto no artigo 221 da Constituição Federal, respeitando valores éticos e sociais da pessoa e da família brasileira e impulsionando à cultura no país (FIORILLO, FULLER, 2015).
\end{abstract}

Portanto, a mídia deve ter como função primeira estar a serviço do homem e não ao revés, baseando-se nosso pensamento em Kant, que funda seu pensamento na questão de ser o homem um fim e não um meio ${ }^{8}$. Assim, a sociedade da informação e a sua consectária, a sociedade em rede, deve ter seu espaço virtual regulado sob a ótica do princípio dignidade da pessoa humana ${ }^{9}$ e da lógica dos imperativos do art. 170 da CF.

\footnotetext{
${ }^{7}$ Esta ideia estabelece que existem diferentes "significados culturais em diferentes contextos de uso", sendo a internet o objeto de um deles.

${ }^{8}$ FULLER, Greice Patrícia. O direito criminal difuso, a dignidade da pessoa humana e a mídia na Sociedade da Informação. In: Anais do VII Congresso Brasileiro da Sociedade da Informação, São Paulo, vol. 7, nov./2014, p.3.

${ }^{9}$ Segundo Greice Patrícia Fuller, a dignidade da pessoa humana, "embora reconhecida como conceito a priori teve sua existência reconhecida e formalizada pela Constituição Federal de 1988 como o valormatriz dos fundamentos da República Federativa do Brasil. In: FULLER, Greice Patrícia. O Meio Ambiente Hospitalar em face da Dignidade da Pessoa humana no Direito Ambiental Brasileiro. Revista Brasileira de Direito Ambiental, abr/jun 2011, p. 62.
} 
Ademais, o artigo $2^{\circ}$ da Lei $n^{\circ} 12.965 / 2014$ estabeleceu como fundamentos do uso da internet: a) liberdade de expressão; b) reconhecimento da escala mundial da rede; c) os direitos humanos, o desenvolvimento da personalidade e o exercício da cidadania em meios digitais; d) a pluralidade e a diversidade; e) a abertura e a colaboração; f) a livreiniciativa, a livre concorrência e a defesa do consumidor; g) a finalidade social da rede. Desse modo, qualquer conduta utilizada por meio da sociedade da informação, que se comunica em redes, que viole os ditames acima mencionados, deve ser considerada como ilícita.

Alguns dos crimes que podem ser praticados por internet em face de movimentos sociais são especialmente os crimes de cyberbulling; terrorismo e neonazismo digitais, crimes de violência cometidos contra travestis e transexuais, apologia aos crimes contra animais de rua, sendo que todos caracterizam movimentos alicerçados na cultura do ódio propagada através de informações (e não comunicação) postulados via internet, sites, blogs, redes sociais que autorizam o download de conteúdos abusivos e criminais.

Fernando LLiñares Miró(2012, p.127) autoriza dizer sobre o assunto que:

Internet puede convertirse por tanto en un instrumento para la lucha política o ideológica de muchas formas distintas: puede ser vehículo de transmisión de la información que a su vez puede ser una forma de captación ideológica muy poderosa, puede ser un medio para el ataque a servicios estatales o institucionales de todo tipo en un momento en el que todos los Estados dependen de alguna forma y en muchas de sus funciones del funcionamiento de Internet, y puede ser un medio sencillo de comunicación entre individuos o grupos separados geográficamente pero unidos por una misma finalidad política o ideológica.

Nesse contexto, adota-se um corte epistemológico no âmbito da cibercriminalidade política e social que se realiza a partir da análise de crimes inerentes ao neonazismo digital, ciberterrorismo e racismo e discriminação digitais.

No que tange ao crime de neonazismo digital, segundo a antropóloga Adriana Dias ${ }^{10}$, em 2002 já existiam cerca de 7 mil páginas de internet com conteúdo neonazista no Brasil e em 2011, já eram cerca de 40 mil com endereços contando com dois milhões de páginas secundárias e fóruns de discussão de ultradireita. Portanto de 2002 a 2011

\footnotetext{
10 APUD, MELO, Alessandra. Internet viabiliza aumento no número de crimes de ódio no Brasil. Disponível. em<http://www.em.com.br/app/noticia/gerais/2013/04/16/interna_gerais,372038/internetviabiliza-aumento-no-numero-de-crimes-de-odio-no-brasil.shtml> Acesso em 20 de março de 2016.
} 
houve um crescimento de cerca de $400 \%$ de atividade de conteúdo nazista, sendo que no Sul e Sudeste do Brasil, a atuação dos skinheads é mais organizada.

Segundo a tipificação nacional, neonazismo consiste na publicação de qualquer natureza, utilizando-se da internet, para distribuir ou veicular símbolos, emblemas, ornamentos, distintivos ou propaganda que utilizem a cruz suástica ou gamada, para fins de divulgação do nazismo. - Artigo 20, § 1 da Lei 7.716/1989.

Em relação aos crimes de racismo praticados por grupos na internet, a organização não governamental Safernet Brasil ${ }^{11}$ avalia que desde 2005 houve aumento dos casos.

Outro crime que também pode ser cometido dentro do contexto dos movimentos sociais e da internet é o referente ao ciberterrorismo, repudiado pela Constituição Federal no artigo $4^{\circ}$, inciso VII e elencando-o como crime inafiançável, segundo o artigo $5^{\circ}$, inciso XLIII da citada Carta Magna.

Sobre o tema, há a Lei 13.260/2016 que estabelece a tipificação dos crimes de terrorismo como a prática de uma ou mais pessoas de atos de sabotagem, de violência ou potencialmente violentos, "por razões de por razões de xenofobia, discriminação ou preconceito de raça, cor, etnia e religião, quando cometidos com a finalidade de provocar terror social ou generalizado, expondo a perigo pessoa, patrimônio, a paz pública ou a incolumidade pública".

Importante salientar que a citada lei exclui atos de movimentos políticos e sociais do objetivo desta lei, segundo o artigo $2^{\circ}, \S 2^{\circ}$. Outro crime que pode ser analisado sob o contexto de movimentos sociais e ideológicos é o crime de racismo e discriminação digitais.

A Constituição Federal de 1988 regulamentou em diversos dispositivos sobre o tema, a saber: a) artigo $1^{\circ}$, inciso III (princípio da dignidade da pessoa humana como fundamento da República Federativa do Brasil); b) artigo $3^{\circ}$, inciso IV que estabelece como objetivo da República a promoção do bem de todos, sem preconceitos de origem, raça, sexo, cor, idade e quaisquer outras formas de discriminação; c) artigo $4^{\circ}$ prescreve o repúdio ao racismo, no tocante às relações internacionais; d) artigo $5^{\circ}$, caput prevê que “todos são iguais perante a lei, sem distinção de qualquer natureza(...); e) artigo $5^{\circ}$, incisos XLI, XLII determinam formas de punição ao racismo, determinando sua inafiançabilidade e imprescritibilidade.

${ }^{11}$ SAFERNET BRASIL. Indicadores da Central Nacional de denúncias de crimes cibernéticos. Disponível em http://indicadores.safernet.org.br/. Acesso em 21 de março de 2016. 
No que tange à legislação infraconstitucional faz-se mister aduzir a Lei 7.716/89 (Lei Antidiscriminação). Para além deste ordenamento jurídico, é possível subsumir a conduta de racismo e discriminação aos seguintes tipos penais: a) Lei 9455/97 (Lei de Tortura), artigo $1^{\circ}$, letra "c"; b) Lei 7853/89 (Lei de Proteção aos Portadores de Deficiência), artigo $8^{\circ}$; c) Lei 2889/56 (Genocídio), artigo 1º ;) Lei 8078/90 (Código de Defesa do Consumidor), artigo 37, $\S 2^{\circ}$; e) Código Penal, artigo 140, $\S 3^{\circ}$ (injúria por preconceito); f) Lei 10741/2003 (Estatuto do Idoso), artigo 100; g) Lei 4898/65 (Lei de Abuso de Autoridade); h) Lei 6001/73 (Estatuto do Índio), artigo 58.

Portanto, através de um corte epistemológico sobre o tema, observa-se que os crimes praticados no contexto dos movimentos sociais na sociedade em rede encontram tipificação legal e imperativa tutela constitucional.

\section{CONCLUSÃO}

O legitimo exercício da cidadania individualmente ou através de movimentos sociais consiste exatamente na liberdade de se mobilizar e demonstrar no espaço público urbano seu inconformismo contra atos administrativos deletérios, leis desarrazoadas ou decisões consideradas injustas e, por consequência, influenciar nas decisões políticas de Governo, de seus representantes no Parlamento e das demais esferas públicas.

A internet e demais TIC's(Tecnologias de Informação e Comunicação) ínsitas à sociedade em rede se constituem nas formas preferenciais de acesso à informação pelos cidadãos e formam os códigos culturais que influenciam aspectos da vida social e cultural com potencial para estimular novos padrões de comportamento, notadamente a opinião pública.

Os movimentos sociais manifestados através das tecnologias de informação devem obediência expressa aos princípios e fundamentos constitucionais presentes nos artigos $1^{\circ}, 3^{\circ}, 5^{\circ}, 6^{\circ}, 170,215,216$ todos da Constituição Federal, para que assim possam ser caracterizados como legítimos e legais, sob pena de serem considerados instrumentos de retrocesso à cidadania e à inclusão digital.

Há vários crimes que podem ser cometidos no âmbito dos movimentos sociais através de redes digitais telemáticas como crimes de terrorismo, neonazismo e racismo, dentre outros, sendo que o núcleo em comum é o discurso do ódio alicerçado ao uso do poder que leva a situações discriminatórias, de medo e racismo. 


\section{REFERÊNCIAS}

ARENDT, Hannah. A Condição Humana. 11 $1^{\mathrm{a}}$ edição, Rio de Janeiro, Forense Universitária, 2010.

BOBBIO, Norberto. MATTEUCCI, Nicola. PASQUINO, Gianfranco. Dicionário de Política, Vol I. Tradução: Carmen C. Varriale, Gaetano Lo Mônoco, João Ferreira, Luis Guerreiro Pinto Cacais e Renzo Dini. 11ª edição, Editora UnB, 1998.

CARDOSO, Gustavo. A mídia na sociedade em rede. Rio de Janeiro, Ed. FGV, 2007.

CASTELLS, Manuel. Compreender a Transformação Social. Conferência de 4 e 5 de Março de 2005, em Portugal-Lisboa, sobre o título: Sociedade em Rede: do Conhecimento à Acção Política, organizado por Manuel Castells e Gustavo Cardoso.

A era da informação: Economia, Sociedade e Cultura, Volume II -O

poder da Identidade. Tradução: Klauss Brandini Gerhardt, $8^{\mathrm{a}}$ ed, Paz e Terra, São Paulo, 2013.

- Redes de Indignação e Esperança. Movimentos sociais na era da internet. Tradução Carlos Alberto Medeiros, 1 aed., Rio de Janeiro, Zahar, 2013.

CHINOY, Ely. SOCIEDADE Uma Introdução à Sociologia. Tradução de Octavio Mendes Cajado, 17a ed., Cultrix, São Paulo, 1991.

FIORILLO, Celso Antonio Pacheco; FULLER, Greice Patrícia. Tutela Constitucional da Internet no Brasil em face do Meio ambiente digital. In: Os 20 anos da internet no Brasil, seus reflexos no Meio Ambiente Digital e sua tutela jurídica na sociedade da informação. São Paulo: FMU, 2015, v. 1.

FULLER, Greice Patrícia. O Meio Ambiente Hospitalar em face da Dignidade da Pessoa humana no Direito Ambiental Brasileiro. Revista Brasileira de Direito Ambiental, abr/jun 2011.

- O direito criminal difuso, a dignidade da pessoa humana e a mídia na Sociedade da Informação. In: Anais do VII Congresso Brasileiro da Sociedade da Informação, São Paulo, vol. 7, nov./2014.

FRAGOSO, Suely; RECUERO, Raquel; AMARAL, Adriana. Métodos e pesquisa para internet. Porto Alegre: Sulina, 2010.

LAFER. Celso. A reconstrução dos direitos humanos: a contribuição de Hannah Arendt, Estudos Avançados, "print version” ISSN 0103-4014, vol.11 n³0, São Paulo, Maio/Agosto. 1997.

., Hannah Arendt, Pensamento, Persuasão e Poder. Rio de Janeiro, Ed.

Paz e Terra, 1979, Coleção o Mundo, hoje; v. 35. 
LYOTARD, Jean-François. O pós-moderno, Tradução: Ricardo Correia Barbosa. Rio de Janeiro: José Olympio, 1993.

MARTín-BARBERO, Jesús. Políticas de la comunicación y la cultura: claves de la investigación. Documentos CIDOB. Dinámicas Interculturales, v. 11. Barcelona: Fundación CIDOB/Cátedra Unesco de Comunicación, 2008.

MIRÓ Llinares, Fernando. El cibercrimen: fenomenología y criminología de la delincuencia en el ciberespacio. Madrid: Marcial Pons, 2012.

PIMENTA, Francisco J. Paolielo; RIVELLO, Ana Paula Avellar. Zapatismo $e$ ciberativismo: a busca de uma conexão perdida. Anais do XXXI Congresso Brasileiro de Ciências da Comunicação, 2008.

\section{Referências bibliográficas digitais: Disponíveis em:}

<http://www.jb.com.br>. Acesso: 19 Jul. 2013.

<http:// www.scielo.br>. Acesso: 21 Out. 2011.

<http://www.escolasderede.net/group/bibliotecahannaharendt>. Acesso: 08 abr 2016.

<http://www.cies.iscte.pt $>$. Acesso: 3 Set. 2013.

$<$ http://www.em.com.br/app/noticia/gerais/2013/04/16/interna_gerais,372038/internetviabiliza-aumento-no-numero-de-crimes-de-odio-no-brasil.shtml >. Acesso: 20 Mar 2016.

<http://indicadores.safernet.org.br/>. Acesso: 5 Abr. 2016. 